\title{
Impact of internet on doctor-patient relationship
}

\author{
Sandesh Banginwar' ${ }^{1}$ Dashputra Amruta ${ }^{1 *}$, Borker Archana ${ }^{1}$, \\ Nayse Jaideep ${ }^{2}$, Badwaik Rupesh ${ }^{1}$
}

\begin{abstract}
${ }^{1}$ Department of Pharmacology, ${ }^{2}$ Department of Community Medicine, NKP Salve Institute of Medical Sciences, Nagpur, Maharashtra, India
\end{abstract}

Received: 02 February 2020

Revised: 14 March 2020

Accepted: 18 March 2020

\author{
*Correspondence: \\ Dr. Dashputra Amruta, \\ Email: avdashputra@gmail.com
}

Copyright: () the author(s), publisher and licensee Medip Academy. This is an open-access article distributed under the terms of the Creative Commons Attribution Non-Commercial License, which permits unrestricted non-commercial use, distribution, and reproduction in any medium, provided the original work is properly cited.

\begin{abstract}
Background: Widespread use of internet as a source of health information has an effect on health-related knowledge, attitude and practices of general population as well as doctor-patient relationship. This study has been planned to see perception of doctors about patients who take medical information by internet search. The objective of the study was to assess impact of internet on doctor-patient relationship among doctors of tertiary health care centre.

Methods: After ethical approval a questionnaire based cross sectional study was conducted among teachers of a tertiary care hospital. Questionnaire was categorized in the two groups: i) negative impact of internet (14), ii) positive impact of internet (11), total= 25 statements, rated on Likert scale. Medical teachers who are involved in treating patients were included $(n=54)$. Data was analysed using mean score and standard deviation for each item.

Results: Most of the doctors opined that use of internet as a source of information has affected doctor-patient relationship (mean 4.35 SD 0.48) and that they were now questioned by already well-informed patients (4.76 SD 0.43). Google search by patients may results in misguided self-treatment or wrong diagnosis (mean 4.85 SD 0.36).

Conclusions: Doctors were agreed that patients are still having same faith on doctors in spite of doing google search on medical information.
\end{abstract}

Keywords: Internet, Health care, Attitude, Self medication

\section{INTRODUCTION}

Internet use by patients as a source of information on health and disease is expanding rapidly. This may lead to rapid changes in health behavior of general population with somewhat negative effect on doctor-patient relationship. ${ }^{1}$ Multiple health-related website are available, which are utilized by millions of people every day. Routine use of internet as a source of health information has an effect on health-related knowledge, attitude and practices of general population as well as doctor-patient relationship. ${ }^{2}$ Majority of the patients google search for specific medical conditions. Most of the times they google search before medical consultation. Purpose of this google search by people is to seek information to manage their own health care independently and also to decide whether they need professional help. Sometimes google search is carried out because of dissatisfaction during medical consultation. ${ }^{3}$

Looking into present scenario patients have information about medical condition before going to doctor's clinic. Reason for change in scenario may be growing influence of information and communication technology and in particular the internet. This widespread use of internet has caused change in attitude towards medical profession as well as in doctor-patient relationship. ${ }^{4}$ The doctorpatient relationship is a very important aspect of improving healthcare quality. ${ }^{5}$ Very few studies have been done on this aspect. Hence this study had been planned to see perception of doctors about patients who had medical information by internet search. In this era of 
information technology, in view of changing scenario of doctor-patient relationship it is prudent to do this type of study. Result of study may be helpful for redesigning the approach of clinician towards patients.

The objective of the study was to assess impact of internet on doctor-patient relationship among doctors of tertiary health care centre.

\section{METHODS}

A questionnaire based cross sectional study was conducted among teachers of NKP salve institute of medical sciences and research centre (NKPSIMS and RC) a tertiary care hospital. This study was started after ethical approval from institutional ethics committee of NKP SIMS and RC (IEC approval Ref no: 2/2019 dated 30/5/2019). Study duration was from June 2019 to August 2019. Questionnaire was prepared by authors and pre-validated by teachers of medical education technology (MET) unit of this institute. Study participants were surveyed using a questionnaire comprises 25 statements rated on Likert scale.

These 25 statements were categories in two groups. Negative impact of internet $=14$ statements. Positive impact of internet $=11$ statements $($ Total $=25)$.

Although questionnaire was categorized into two categories for analysis purpose but sequence of statements was random to avoid personal bias.

Likert scaling is a bipolar scaling method, measuring either a positive or a negative response to a statement. ${ }^{6} \mathrm{~A}$ score of more or less than three indicate a positive or negative response to a statement respectively. A score of three or very near to three indicate neutral response. Summative scores were prepared for both groups (summative score was the sum of mean score of items). The format of a typical five level Likert item is: strongly disagree (strongly unfavourable to the concept). Disagree (Somewhat unfavourable to the concept). Neither agrees nor disagrees (undecided). Agree (somewhat favourable to the concept). Strongly agree (strongly favourable to the concept).

After explaining purpose of study consent of participant faculty was taken. Medical teachers who involved in treating patients were included $(n=54)$. Anonymity and confidentiality of participant was maintained.

\section{Statistical analysis}

Statistical analysis was done by using Epi-info software, version 6. Data was analysed using mean score and standard deviation for each item and summative score was prepared for both group negative impact and other groups comprising positive impact.

\section{RESULTS}

Advancement in information technology had many positive and negative effects on doctor-patient relationship. Most of the doctors opined that use of Internet as a source of information has affected doctor patient relationship (mean 4.35 SD 0.482). According to clinician with the arrival of the information era patient's confidence in the doctor is replaced by skepticism and discouragement (mean 3.96 SD 0.54). Most of them strongly agreed that patients who had done internet search before visit takes more consultation time (mean 4.76 SD 0.43) and they suggests new investigation and ask for opinion of super specialist (mean 4.54 SD 0.50) and a distrustful patient misuses the information obtained from internet to test the clinicians' knowledge (mean 4.24 SD 0.58). Most of the clinician agreed that doctors had different attitude for the patients who had already done Google search for medical complains (mean 4.11 SD 0.46). Most of clinician worry about the reliability of medical information provided on internet (mean 4.28 SD $0.45)$. This may result in misguided self-treatment or wrong diagnosis (mean 4.85 SD 0.36). This was the highest score in this study. Doctors strongly agreed that it is difficult to treat patients who take self-medication after internet search (mean 4.67 SD 0.46) and these types of patients were more anxious type personalities (mean 4.78 SD 0.42). Clinician opined that they might get irritated by questions of such type of patients (mean 4.20 SD 0.15). But most of doctors were in disagreement about the statement that they try to avoid them (mean 2.17 SD 0.54) and medical information by internet has affected patients' number in outpatient department (OPD) (mean 2.02 SD 0.31).

In an era of information technology most doctors opined that they were now questioned by already well-informed patients (4.76 SD 0.43) and near about $50 \%$ of patients coming to doctors OPD had already done search on internet (mean 4.52 SD 50). Most of them strongly agreed regarding that there is need of rethinking of Doctor- Patients relationship (mean 4.52 SD 0.66). Most of clinicians opined that patients are still having same faith on doctors in spite of doing google search on medical information (mean 3.98 SD 0.62). Most of doctors showed agreement regarding statement that lack of satisfaction with medical consultation might be the reason for internet search by patients (mean 3.94 SD 0.45 ) and patients having good socioeconomic status were doing maximum medical information search (mean 4.44 SD 0.74). Doctors opined that patients were able to interpret medical information available on internet (mean 4.13 SD 0.74). Doctors opined that clinician use internet is for updating professional knowledge (mean 3.69 SD 0.51 ) and treatment of patient (mean 4.17 SD 0.63). Sometimes patients come with medical information which is new information for doctor (3.94 SD 0.66). 
Table 1: Negative impact of internet.

\begin{tabular}{|c|c|c|c|c|c|}
\hline $\begin{array}{l}\text { S. } \\
\text { no. }\end{array}$ & Question & $\mathbf{N}$ & Mean & Std. deviation & $(\%)$ \\
\hline 1 & $\begin{array}{l}\text { Use of Internet as a source of information has affected Doctor } \\
\text { patient relationship }\end{array}$ & 54 & 4.35 & 0.482 & 87.0 \\
\hline 2 & $\begin{array}{l}\text { With the arrival of the information era patient's confidence in the } \\
\text { doctor is replaced by skepticism and discouragement. }\end{array}$ & 54 & 3.96 & 0.548 & 79.3 \\
\hline 3 & $\begin{array}{l}\text { Internet savvy patients themselves suggests new investigation and } \\
\text { ask for ask for opinion of super specialist. }\end{array}$ & 54 & 4.54 & 0.503 & 90.7 \\
\hline 4 & $\begin{array}{l}\text { Patients who had done internet search before visit takes more } \\
\text { consultation time }\end{array}$ & 54 & 4.76 & 0.432 & 95.2 \\
\hline 5 & $\begin{array}{l}\text { There is concern about the quality/reliability of medical information } \\
\text { provided on internet. }\end{array}$ & 54 & 4.28 & 0.452 & 85.6 \\
\hline 6 & $\begin{array}{l}\text { Most of patients believe health information available on internet is } \\
\text { reliable as equal to information provided by doctors. }\end{array}$ & 54 & 4.70 & 0.461 & 94.1 \\
\hline 7 & $\begin{array}{l}\text { Internet search by patients may results in misguided self-treatment/ } \\
\text { wrong diagnosis }\end{array}$ & 54 & 4.85 & 0.359 & 97.0 \\
\hline 8 & $\begin{array}{l}\text { Doctors have different attitude for the patients who had already } \\
\text { done google search for medical complains }\end{array}$ & 54 & 4.11 & 0.462 & 82.2 \\
\hline 9 & $\begin{array}{l}\text { A distrustful patient misuses the information obtained from internet } \\
\text { to test the clinicians' knowledge }\end{array}$ & 54 & 4.24 & 0.581 & 84.8 \\
\hline 10 & $\begin{array}{l}\text { It is difficult to treat patients who take self-medication after internet } \\
\text { search. }\end{array}$ & 54 & 4.67 & 0.476 & 93.3 \\
\hline 11 & Internet savy patients are more anxious type personalities. & 54 & 4.78 & 0.420 & 95.6 \\
\hline 12 & Sometimes you get irritated by questions of internet savvy patients. & 54 & 4.20 & 1.105 & 84.1 \\
\hline 13 & Treatment by internet has affected patients' number in OPD. & 54 & 2.02 & 0.307 & 40.4 \\
\hline 14 & $\begin{array}{l}\text { Doctor tries to avoid such type of internet savvy (medical } \\
\text { information) patients. }\end{array}$ & 54 & 2.17 & 0.541 & 43.3 \\
\hline \multicolumn{2}{|r|}{ Average } & 54 & 4.12 & 0.24 & 82.3 \\
\hline
\end{tabular}

Table 2: Positive impact of internet.

\begin{tabular}{|c|c|c|c|c|c|}
\hline $\begin{array}{l}\text { S. } \\
\text { no. }\end{array}$ & Question & $\mathbf{N}$ & Mean & Std. deviation & $(\%)$ \\
\hline 1 & $\begin{array}{l}\text { Lack of satisfaction with medical consultation may be reason for } \\
\text { internet search. }\end{array}$ & 54 & 3.94 & 0.452 & 78.9 \\
\hline 2 & Doctors are now being questioned by already well-informed patients. & 54 & 4.76 & 0.432 & 95.2 \\
\hline 3 & $\begin{array}{l}\text { Now a days near about } 50 \% \text { of patients coming to doctors OPD had } \\
\text { already done search on internet }\end{array}$ & 54 & 4.52 & 0.504 & 90.4 \\
\hline 4 & Your advice treatment to your patients via email. & 54 & 1.22 & 0.538 & 24.4 \\
\hline 5 & $\begin{array}{l}\text { Patients are able to interpret medical information available on } \\
\text { internet. }\end{array}$ & 54 & 4.13 & 0.478 & 82.6 \\
\hline 6 & $\begin{array}{l}\text { Patients having good socioeconomic status are doing maximum } \\
\text { medical information search }\end{array}$ & 54 & 4.44 & 0.744 & 88.9 \\
\hline 7 & $\begin{array}{l}\text { Patients are still having same faith on doctors in spite of google } \\
\text { search on medical information }\end{array}$ & 54 & 3.98 & 0.629 & 79.6 \\
\hline 8 & $\begin{array}{l}\text { There is need of rethinking of doctor-patients relationship in the eye } \\
\text { of humanization. }\end{array}$ & 54 & 4.52 & 0.666 & 90.4 \\
\hline 9 & $\begin{array}{l}\text { Sometimes patients come with medical information which is new } \\
\text { information for doctor }\end{array}$ & 54 & 3.94 & 0.656 & 78.9 \\
\hline 10 & Internet is used by doctors for updating professional knowledge. & 54 & 3.69 & 0.507 & 73.7 \\
\hline 11 & Doctors occasionally use internet for treatment of patients. & 54 & 4.17 & 0.637 & 83.3 \\
\hline \multicolumn{2}{|r|}{ Average } & & 3.93 & 0.17 & 78.6 \\
\hline
\end{tabular}




\section{DISCUSSION}

Thousands of websites and millions of daily Internet health related information searches leads to an enormous and rapid change in health behavior of patients. Most Internet searches performed by patients before their clinic appointment are directed to specific clinical condition. ${ }^{4}$ This finding is also reflected in present study that doctors were now questioned by already well-informed patients (4.76 SD 0.43) and near about $50 \%$ of patients coming to doctors OPD had already done search on internet (mean 4.52 SD 50). Same results were found in another study. ${ }^{1}$ Reason for internet search done by patients with objective of dealing with medical problem independendently, so they can decide whether there is a need to take medical advice by clinician or not. Another possibility of doing internet search by patient is that they might be reluctant to disclose personal matters to clinician. $^{1}$

In another study Internet search by patients may continue after medical consultation was over because of a patient was not satisfied with the recent medical consultation or even to confirm the validity of what has been told by doctor. ${ }^{7}$ In present study same type of result found that lack of satisfaction with medical consultation might be the reason for internet search by patients (mean 3.94 SD $0.45)$.

Many patients or their relatives, especially in an urban area have an easy access to the internet and routinely make use of it to obtain medical information. Socioeconomic factors were associated with searching for health information. ${ }^{8-10}$ In present study patients having good socioeconomic status were doing maximum medical information search (mean 4.44 SD 0.74). Majority of people who search on Google for medical information wanted knowledge before visit to doctor's clinic. ${ }^{10}$

Although internet search has the benefit of easy access to information, there are concerns regarding quality of the content and its effects on the doctor patients' relationship. ${ }^{4}$ This unreliable information may lead to misguided self-treatment and wrong diagnosis, longer clinic visit. It also reflects on doubt about doctor's diagnosis and treatment. Unnecessary tests and treatment which are mentioned on internet may leads to increased financial burden on patient. It is responsibility of clinician to provide unbiased and scientific guidelines to their patients about medical condition. ${ }^{11,12}$ It was found that medical information on internet was scientifically inaccurate, incomplete and biased. Regarding treatment information was controversial and had commercial angle to it. ${ }^{9,10}$ This type of information may be one of the factors responsible for problematic perception of patients regarding doctor. ${ }^{13,14}$

In this study most of clinicians worry about the reliability of medical information provided on internet (mean 4.28 SD 0.45). This type of information may result in misguided self-treatment or wrong diagnosis (mean 4.85 SD 0.36). This was the highest score in this study.
Doctors strongly agreed that it is difficult to treat patients who take self-medication after internet search (mean 4.67 SD 0.46). Sometimes this type of patients may have complication because of wrong self-treatment. It was difficult for clinician to convince patient that information and treatment mention on internet is not appropriate for him. In this situation patients may have doubt about clinician's diagnosis and treatment.

\section{Doctor-patients' relationship}

A number of studies focus on whether the information available on internet can actually empower patients understanding and enrich the patient doctor relationship. ${ }^{13,14}$ In present study doctors strongly agreed that patients who had done internet search before visit takes more consultation time (mean 4.76 SD 0.43) and patients suggest new investigation and ask for opinion of super specialist (mean 4.54 SD 0.50) and a distrustful patient misuses the information obtained from internet to test the clinicians' knowledge (mean 4.24 SD 0.58) people now use the internet to find information about their disease and they do it before going to the medical consultation. Now a day's doctors are no longer the sole holder of supreme knowledge rather they are being questioned by increasingly well-informed patients. ${ }^{4}$

Clinicians opined that they might get irritated by questions of such type of patients (mean 4.20 SD 0.15). Physicians are often not receptive to discussing internet information brought to a visit by their patients. Clinicians might be feeling that they are dominated by patients. It may lead to poor doctor-patient relationship. ${ }^{13}$

It has been noticed that internet search for health has affected dynamics of doctor-patient relationship. There is increase in number of complaints against doctors in various countries, along with the increase in health expenses. Even in few countries' doctors' services have been included in consumer protection act. With the arrival of the information technology, patients came under the influence of digital revolution. The immediate impact of this digital revolution is that confidence in doctor is replaced by suspicion, doubt and discouragement. Blind faith in doctor's treatment is replaced by informed knowledge. Traditionally family doctor was first medical contact, which is being replaced by internet in many cases. In present scenario patient first do search on medical websites and then consult their doctors with that information. ${ }^{1,4}$

To improve healthcare quality, doctor-patient relationship has been targeted as a key aspect. This includes personalized care, humanization of care, counseling and right to information. ${ }^{11}$ For improvement in doctor patient's relationship communication skill has been developed as key component in undergraduate and postgraduate studies in the current new medical curriculum.

Another side of this coin is that internet and information technology is helpful for patient care in hospitals and to 
optimize communications between health care providers. ${ }^{12}$ Important positive aspect of internet search is that many doctors had critically evaluated the websites and medical information on internet and found them scientifically inaccurate. ${ }^{10}$ According to a study conducted on patients, it revealed that they obtained information online before visiting the doctors and few of them searched online information about doctor and hospital. ${ }^{11,15}$ Patients who search on internet, according to them it will be helpful for them to ask questions or even opt for a second opinion. In another study google search had a positive impact on the knowledge of the patients about the disease. ${ }^{10}$ This will be helpful for clinician to explain about disease and treatment. In one study $73 \%$ patients said that doctors were favorite source of health information, not internet. There was no loss of trust in physician even after difference of information available on the internet. ${ }^{13}$

Clinician's insight, experience and encouragement are needed to help the patient to accurately interpret and apply this information. ${ }^{1}$ Patients should realize that the doctor has the knowledge and training and ability to apply this information. ${ }^{16}$ Positive aspect of medical information on internet is that there is greater involvement of patient in understanding long term conditions. Better adaptation of preventive factors and adherence to the guidelines given by clinician. ${ }^{15}$

\section{CONCLUSION}

Most of the doctors opined that use of Internet as a source of information has affected doctor patient relationship and they were now questioned by already well-informed patients. Google search by patients results in misguided self-treatment or wrong diagnosis. Lack of satisfaction with medical consultation may be reason for internet search by patients. Doctors were agreed that patients are still having same faith on doctors in spite of doing google search on medical information.

\section{Recommendations}

Judicial use of internet search by patient for medical information is the key factor to maintain doctor patient relationship. Doctors should utilize medical information on internet as an add on tool to treat patients.

Funding: No funding sources

Conflict of interest: None declared

Ethical approval: The study was approved by the Institutional Ethics Committee

\section{REFERENCES}

1. Vargas FG. The effect of internet on the patientdoctor relationship in a hospital in the city of Sao Paulo. JISTEM. 2014;11(2):327-44.

2. Eysenbach G. The impact of the internet on cancer outcome. CA cancer J clin. 2003;53(6):356-71.
3. Mullan MM. Patients using the Internet to obtain health information: how this affects the Patienthealth professional relationship. Patient Edu Couns. 2006;63(1-2):24-8.

4. Kim J, Kim S. Physicians' perception of the effects of internet health information on the doctor-patient relationship. Inform Healh Soc Care. 2009;34(3):13648.

5. Goodman KW. Ethics, information technology and public health: new challenges for the clinicianpatients relationship. In: Symposium the effects of health information technology on physician-patients relationship. J Law Medicine Ethics; Spring 2010.

6. Rensis L. A technique for the measurement of attitudes. Arch Psychol. 1932;140:1-55.

7. Grossman JM, Zayas CT, Kemper N. Information gap: can health insurer personal health records meet patients' andphysicians' need. Health Affairs. 2009;28(2):377-89.

8. Dunne S, Hannigan A, Cummins N, Shannon B, Dunne C, Cullen W. A method for the design and development of medical or health care information websites to obtain search engine results page ranking on google. J Medical Internet Res. 2013;15(8):2196632 .

9. Wang L, Wang J, Wang M, Lian Y, Xu D. Use experience evaluation of google search for obtaining medical knowledge: a case study. Int $\mathrm{J}$ Education Min Bioform. 2011;5(6):626-39.

10. Kothari M, Moolani S. Reliability of google for obtaining medical information. Indian J Opthalmol. 2015;63(3):267-9.

11. Fox S, Rainie L. Internet and American Life Project: Vital Decisions: A Pew Internet health report. Pew Research centre. Internet Technology. 2002;275-82.

12. Macgregor RC, Hyland PN, Harvie C. Association between driving forces to adopt ICT and benefit derived from that adoption in medical practices in Australia. In Handbook of research on development in e-health and telemedicine: technological and social perspective. IGI Global. 2010;652-68.

13. Shoor S, Lorig KR. Self-care and the Doctor-Patient Relationship. Medical Care. 2002;40(4):40-4.

14. Sinclair F. In Need of TLC: A Doctor-Patient Relationship Fit for the future. Scottish Foundation. 2007;1(7):1-13.

15. Xinyi $\mathrm{Hu}$, Bell R, Kravitz R, Orrange S. The Prepared Patient: Information seeking of online support group members before their medical appointments. J Health Communication, Inte Perspectives. 2012;17(8):960-78.

16. Pereira NAF, Guilam MCR. The internet, expert patients and medical practice: An Analysis of the literature. Interfce Comun Saude Edu. 2008;12(26):579-88.

Cite this article as: Banginwar S, Amruta DV, Archana B, Jaideep N, Rupesh B. Impact of internet on doctor-patient relationship. Int J Basic Clin Pharmacol 2020;9:731-5. 